\title{
The Effect of Core Exercise Program on Motoric Skills in Young People
}

\author{
Yıldız Yaprak* \\ Physical Education and Sports Department, Hatay Mustafa Kemal University, Turkey
}

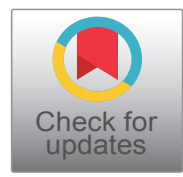

*Corresponding author: Yıldız Yaprak, Physical Education and Sports Department, Hatay Mustafa Kemal University, Antakya, Turkey

\begin{abstract}
Purpose: The objective of this study was to determine the effects of an 8-week core exercise programme performed on Swiss ball and BOSU ball that on dynamic balance, flexibility, spinal Range of Motion (ROM), back muscle endurance, back muscle strength, abdominal muscle strength, and body composition for healthy young males.

Methods: Twenty-two young males (Age: $20.68 \pm 2.27$ years, height: $175.23 \pm 5.17 \mathrm{~cm}$, body weight: $66.81 \pm 7.85$ $\mathrm{kg}$ ) volunteered for the study. Prior to the training period, all participants completed anthropometric measurements, body composition measurement, back muscle strength and endurance tests, sit-up test, lateral bending and spinal ROM measurements, Y Balance Test (YBT). After measurements, the participants were divided into randomly two groups. The exercise group (N:12) performed the core exercise 3 days per week for 8 weeks. The control group $(\mathrm{N}: 10)$ did not participate in any type of exercise. "Indepented t-test" and "Paired-Samples T test" were used for analysis of all parameters between the pre and post training measurements for exercise and control groups.
\end{abstract}

Results: The present findings show that there were significant increases between pre and post-training values for back muscle strength, abdominal muscle strength, spinal $\mathrm{ROM}$ and dynamic balance in the exercise group compare with control group. Following the core strength training programme, back muscle strength $(+10 \%)(p<0.05)$ and endurance $(+18.61 \%)(p<0.00)$, abdominal muscle strength $(+20.39 \%)(p<0.03)$, leg strength $(+12.66 \%)(p$ $<0.01$ ), spine ROM, lateral flexibility and dynamic balance values of the exercise group showed a significant increase when compared with the pre test values. The control group did not show any significant changes pre and post training values when compared with exercise group.

Conclusions: The results demonstrated that the 8-week a core training programme with Swiss ball and BOSU ball was effective to increase flexibility, dynamic balance, strength and muscular endurance, but not effective to decrease body fat. In this context, it can be said that this strength and flexibility training program may be a pleasurable alternative training type by coaches and physiotherapists that increased the above-mentioned physical fitness parameters for athletes or sedanter individuals.

\section{Keywords}

Core strength exercise, Balance test, Flexibility, Muscle endurance, BOSU ball, Swiss ball

\section{Introduction}

The "core" was described as a box with the abdominal muscles in the front, gluteals and paraspinals muscles in the back, the diaphragm at the top, and the pelvic floor and hip muscles as the base [1,2]. Briefly, the "core" has been used to refer to the trunk or more specifically the lumbo-pelvic region [3]. Additionally, "core stability" may described as the level of endurance or strength in particular muscle groups of the lumbopelvic complex $[4,5]$. The strong and endurance of the core region is important. Because, greater core stability provides a foundation for greater force production in the upper and lower extremities [2,3]. When the core muscle are functioning optimally, the person will be able to safely perform athletic or other functional activities. When dysfunctionis present, the person's performance will decrease, and they may also be at an increased risk for injury [6]. At provide stability of the spine, in order to create force and to prevent injury, trunk muscles must have adequate strength and endurance [7]. Failure to adequately train these muscles will limit the effectiveness of the core in doing 
its job [6]. Core strength appear to be more important for improvements in sports-related performance and core endurance appears be more important for injury prevention and rehabilitation $[4,8,9]$.

Furthermore, core muscle function has been reported to influence structures from the low back to the ankle [4]. For example, McGill's reports have explaned that persons with weak endurance capacity of the trunk have an increased risk of back pain [8]. And some considerable researchs on core stability has been performed in the physiotherapy and rehabilitation field, with particular focus on spine pathology and the reduction of low back pain by strengthening the core muscles [10].

Moreover, core muscles exercises have been frequently applied by healthy individuals in fitness and sports centers [3]. One of the major advantageous is that these exercises can be performed anytime by all the age groups and ability levels [11]. The populer exercises such as Pilates, yoga and tai chi have been used for core muscles strengthening [9]. Although, to improvement strength, balance and coordination in core training may used unstable surfaces (BOSU ball, Swiss ball etc). Some study has shown that performing core training on an unstable surface resulted in an increase in EMG activity of core muscles $[5,9,12]$.

The purpose of this 8-week study was to investigate the effects of six different core exercises with Swiss ball and BOSU ball on physical fittness parameters such as strenght, endurance, balance, flexibility and body composition.

\section{Methods}

\section{Participants}

Twenty-two male university students (12 experiment and 10 control) between the ages of 18 and 25 years with no history of back pain or leg pain were recruited. The study was approved by the ethics committee of Medicine Faculty in Mustafa Kemal University, and informed consent was obtained from the participants.

\section{Measurements}

Anthropometric measurements: Height and Body Weight (BW) were measured to the nearest $0.1 \mathrm{~cm}$ and $0.1 \mathrm{~kg}$, respectively. Body Mass index (BMI) was calculated as body weight $(\mathrm{kg})$ divided by squared height $\left(\mathrm{m}^{2}\right)$. Waist circumference was measured midway between the lower rib margin and the superior anterior iliac spine. Hip circumference was taken at the widest point over the greater trochanters with a tape meter [13].

Fat Mass (\%FM) measurement: It was assessed for each participant by bioelectrical impedance analysis (BIA) (Tanita Body Composition Analyzer Mode TBF-300, Tokyo, Japan). Macfarlane found within-day reliability of the Tanita BF-350 with an ICC of 1.00 for BF\% $[14,15]$.

The sit and reach test: This test was utilized to assess flexibility of the lower back and hamstrings muscles. Standard procedures for this test were followed. The participants placed their hands top of the box and slowly reached forward as far as possible while keeping the extended knees. The best score of two efforts was recorded in centimeters $[13,16]$.

Isometric leg and back strength measurement: These tests were assessed using a dynamometer (Takei, Tokyo, Japan). Two trials were administered with a 1 minute rest between the trials [13].

Sit-up and back extension test: For sit-up test, participants laid in a supine position and flexed 90 degrees their knees and hips, and feet touch the wall with angle of 90 degrees. The hands were placed on the side of the head with fingers over the ears. The participants elevated the trunk until the elbows made contact with the legs. For back extension test, the participants were laid in a prone position on a mat with the knees fully extended. Their hands were clasped behind the head and extended their torso on the floor. After completing the extension, the chest was allowed to lower and return to the starting position. The number of maximal repetitions for sit-up and back extension test were recorded $[13,17]$.

Back extensor endurance test (Biering-Sorensen Test): The participants lied prone over the end of a treatment couch with anterior superior iliac spine supported on the bench edge. Their ankles were fixed by the researcher. They maintained the horizontal position for as long as possible, beginning timing when the horizontal unsupported position was achieved and ending when they dropped below the horizontal plane. The duration of holding was measured in seconds $[17,18]$.

Inclinometric measurement: Thoracic and lumbar spine ROM for flexion and extension were measured using inclinometer (bubble inclinometer, enterprises inc. USA). The spinous processes at T12-L1 (Throcal 12-Lumbar 1) and L5-S1 (Lumbar 5-Sacral 1) were located and marked by palpation with the participants standing upright. The inclinometer was placed on the landmark and "zeroed" before motion occurred. The participants performed flexion by bending forward and extension by bending backward as far as they could, respectively. Once full movements were completed, inclinometer was read and recorded. Waddell, et al. found these measurements to be highly reliable (Intraclass Correlation Coefficient [ICC] range, (0.860.95) [19].

Lateral bending measurements: The distance between the tip of the middle finger and the floor was measured in standing position and in fully attained lateral bending using a tape measure. The difference 
Table 1: Core training protocol.

\section{Core Exercises}

Warm-up and stretching

1. Two legs rises from side on BOSU ball

2. Cross sit-up on BOSU ball

3. Back extension on BOSU ball

4. Quadruped opposite arm-leg raise on BOSU ball

5. Dynamic glute bridge on a Swiss ball

6. Static plank on a Swiss ball

\section{First 4 weeks}

10 min walk + static streching

$2 \times 15$ repeats (rigth side and left side)

$2 \times 15$ repeats

$2 \times 15$ repeats

$2 \times 15 \mathrm{sec}$ (both sides)

\section{Second 4 weeks}

10 min walk + static streching

$3 \times 20$ repeats (rigth side and left side)

$3 \times 20$ repeats

$3 \times 20$ repeats

$3 \times 20 \mathrm{sec}$ (both sides)
$2 \times 15$ repeats
$3 \times 20$ repeats
$2 \times 15 \mathrm{sec}$
$3 \times 20 \mathrm{sec}$

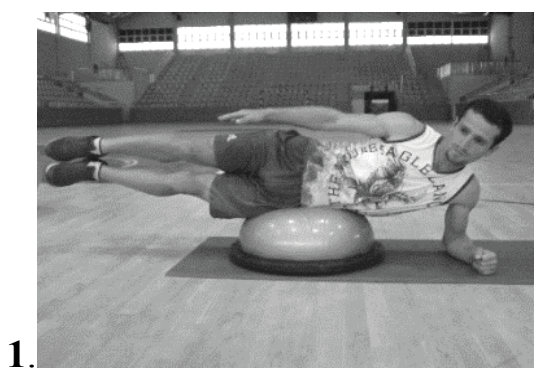

2.
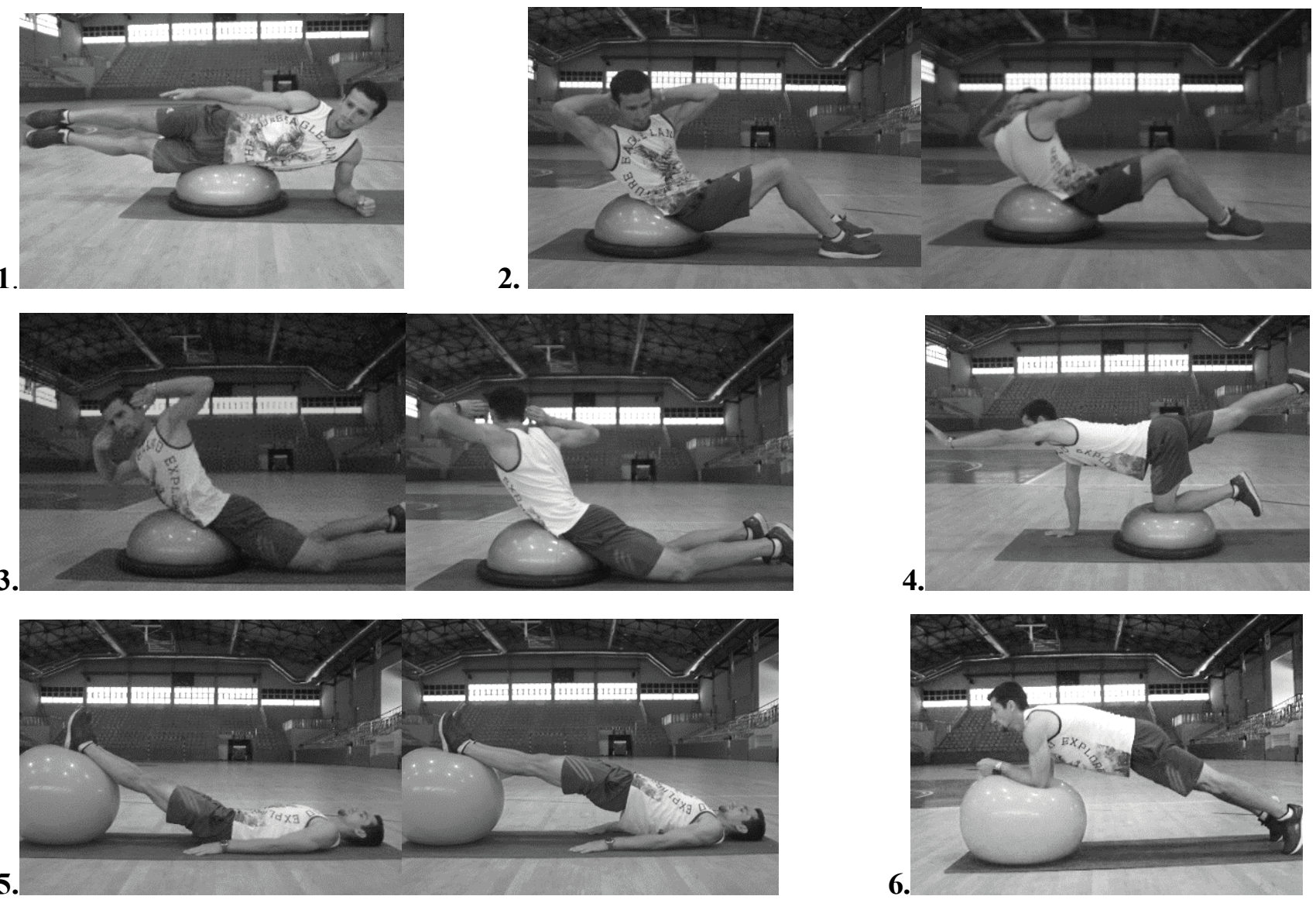

Figure 1: Core exercises.
4.

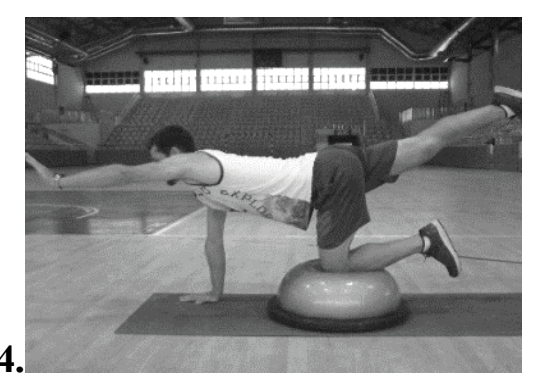

6.

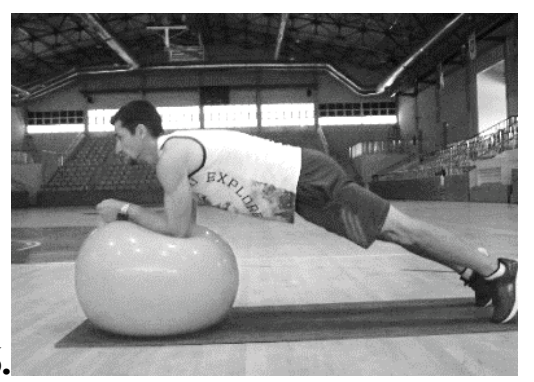

between these two measurements was the lateral bending ROM measurement for that side. Right lateral bending and left lateral bending were measured $[20,21]$.

Dynamic balance test: For the balance test was used Y Balance Test which were anterior, posteromedial, and posterolateral directions. Firsly, the participants placed their left foot on the center and reached with the right foot to anterior, posteromedial, and posterolateral directions. After, same movements were performed other foot. Each test was measured twice in each directions on each leg [22]. Shaffer, et al. found these measurements to be highly reliable ICC range, 0.86-0.93 [23].

Warm-up and stretching exercises were performed by the participants prior to the all performance measurements.

\section{Training program}

Participants were randomly assigned to an exercise group ( $n=12)$ and a control group $(n=10)$. Exercise group participated in a core training program 3 times per week, during 8 weeks. Training consisted of 2 set of 15 repetitions first 4 weeks, and 3 set of 20 repetitions second 4 weeks. The 8 -week program which includes 4 Swiss ball exercises and 2 BOSU ball exercises is shown in Table 1. The participants rested for at least 20 second between sets, and 90 second between the exercises. Control group were not any exercises during 8 weeks (Figure 1).

All participants were retested after the 8 weeks using the same procedures described for the pretest. All measurements were carried out the same time interval and under the same environmental conditions.

\section{Statistical analysis}

SPSS 16.0 statistical software was used to perform all the analysis. Each parameter was calculated as mean \pm 
Table 2: Physical characteristics of exercise and control groups in males.

\begin{tabular}{|l|l|l|}
\hline & $\begin{array}{l}\text { Exercise Group }(\mathbf{n}=\mathbf{1 2}) \\
\text { Mean } \pm \text { SD }\end{array}$ & $\begin{array}{l}\text { Control Group }(\mathbf{n}=\mathbf{1 0}) \\
\text { Mean } \pm \text { SD }\end{array}$ \\
\hline Age $($ year) & $20.75 \pm 2.63$ & $21.20 \pm 3.22$ \\
\hline Height $(\mathbf{c m})^{*}$ & $172.38 \pm 4.48$ & $178.65 \pm 3.74$ \\
\hline BW $(\mathbf{k g})$ & $67.40 \pm 8.05$ & $66.10 \pm 7.96$ \\
\hline BMI $\left(\mathbf{k g} / \mathbf{m}^{2}\right)$ & $22.33 \pm 2.00$ & $20.53 \pm 2.03$ \\
\hline
\end{tabular}

Table 3: Body composition and anthropometric measurements of the participants.

\begin{tabular}{|c|c|c|c|c|c|}
\hline Parameters & Groups & $\begin{array}{l}\text { pre } \\
\text { Mean } \pm \text { SD }\end{array}$ & $\begin{array}{l}\text { Post } \\
\text { Mean } \pm \text { SD }\end{array}$ & $\begin{array}{l}\% \\
\text { Change }\end{array}$ & $P$ value \\
\hline \multirow{2}{*}{$\begin{array}{l}\text { BW } \\
\text { (kg) }\end{array}$} & Exercise & $67.40 \pm 8.05$ & $67.54 \pm 8.54$ & +0.19 & ns \\
\hline & Control & $66.10 \pm 7.96$ & $66.95 \pm 7.85$ & +1.28 & ns \\
\hline \multirow{2}{*}{$\begin{array}{l}\text { BMI } \\
\left(\mathrm{kg} / \mathrm{m}^{2}\right)\end{array}$} & Exercise & $22.33 \pm 2.00$ & $22.60 \pm 2.14$ & +1.20 & ns \\
\hline & Control & $20.53 \pm 2.03$ & $20.64 \pm 2.19$ & +0.53 & ns \\
\hline \multirow{2}{*}{$\begin{array}{l}\text { Fat Mass (FM) } \\
(\%)\end{array}$} & Exercise & $12.48 \pm 5.73$ & $12.57 \pm 6.54$ & +0.72 & ns \\
\hline & Control & $9.75 \pm 3.51$ & $9.10 \pm 3.98$ & -7.14 & ns \\
\hline \multirow[t]{2}{*}{ Fat Free Mass (FFM) (kg) } & Exercise & $58.66 \pm 4.28$ & $58.61 \pm 4.20$ & -0.08 & ns \\
\hline & Control & $59.62 \pm 7.17$ & $60.92 \pm 6.67$ & +0.21 & ns \\
\hline \multirow{2}{*}{$\begin{array}{l}\text { Trunk Fat } \\
(\%)\end{array}$} & Exercise & $12.82 \pm 6.61$ & $13.15 \pm 7.46$ & +2.49 & ns \\
\hline & Control & $9.57 \pm 4.42$ & $8.58 \pm 3.53$ & -11.53 & ns \\
\hline \multirow[t]{2}{*}{ Waist Circumference (cm) } & Exercise & $77.45 \pm 6.75$ & $76.83 \pm 8.50$ & -0.80 & ns \\
\hline & Control & $75.80 \pm 5.49$ & $75.20 \pm 5.32$ & -0.79 & ns \\
\hline \multirow{2}{*}{$\begin{array}{l}\text { Hip Circumference } \\
\text { (cm) }\end{array}$} & Exercise & $94.83 \pm 6.56$ & $94.41 \pm 6.90$ & -0.43 & ns \\
\hline & Control & $94.50 \pm 5.29$ & $94.65 \pm 5.70$ & +0.15 & ns \\
\hline
\end{tabular}

ns: Not significant.

Standart Deviation (SD). The normality of distributions and the homogeneity of variances were assessed by Shapiro-Wilk and Levene tests. Indepented t-test was used to compare the differences in dependent variables between groups. Paired-Samples $T$ test was used for analysis of all parameters between the pre and post measurements for exercise and control groups. Also, nonparametric Wilcoxon test was used for only sit-up test data which not normal distribution. $\mathrm{P}<0.05$ was considered significant. The change in each parameter that measured pre and post training was calculated a percentage.

\section{Results}

The means and standard deviations for physical characteristics and anthropometric measurements according to groups are presented in Table 2. All pre-training parameters of groups were analyzed by independent sample t-test. There was no significant difference between both groups except for height. It can be said that all of baseline values of groups were similar with regard to the baseline characteristics except for height $(p<0.00)$.

The means, SD and changes in body composition and anthropometric measurements are presented in Table 3. At the end of 8 weeks, there were small differences between pre and post-values in both groups. But there was no a statistical significant difference all anthropometric values and body composition measurements.

Strength and endurance values such as isometric leg and back strength and sit-up test, dynamic back extension tests and Biering-Sorensen tests are presented in Table 4. There were significant differences pre and post training datas except for back extension test in this study. However, there were not significant differences pre and post training values in control group for all parameters in this table. There were increases $12.66 \% \mathrm{kgf}$ to the leg strength, $10 \% \mathrm{kgf}$ to the back strength and $18.61 \%$ sec to the back muscle endurance in exercise group after the 8 -week core training. In spide of $14.68 \%$ increasing, back extension test score was not found statistical significant.

At exercise group showed more improvement at strength of leg, back and abdominal muscles than control group, after training.

In Figure 2, pre and post measurements of the flexibility parameters are presented. Statistical analysis showed significant differences between pre and post values for sit\&reach test $(p<0.01)$, right lateral ( $p$ $<0.00$ ) and left lateral ( $p<0.00$ ) flexion in exercise group. Especially, it was found that there was more improvement at left and right bending than forward bending.

Figure 3 show the results of the spinal ROM values 
Table 4: Values of strength and endurance parameters of the participants.

\begin{tabular}{|l|l|l|l|l|l|}
\hline & & pre & Post & P value \\
Parameters & Groups & Mean \pm SD & Mean \pm SD & Change \\
\hline Isometric Leg Strength (kgf) & Exercise & $133.92 \pm 33.98$ & $150.88 \pm 26.01$ & +12.66 & 0.01 \\
& Control & $124.15 \pm 20.73$ & $129.15 \pm 18.38$ & +4.02 & $\mathrm{~ns}$ \\
\hline Isometric Back Strength (kgf) & Exercise & $132.17 \pm 28.14$ & $145.42 \pm 22.83$ & +10.00 & 0.05 \\
& Control & $128.88 \pm 17.28$ & $133.60 \pm 16.26$ & +3.72 & $\mathrm{~ns}$ \\
\hline Sit-up test (maximal number) & Exercise & $47.41 \pm 22.67$ & $57.08 \pm 20.14$ & +20.39 & 0.03 \\
\hline Back Extension test (maximal & Control & $39.90 \pm 17.25$ & $43.20 \pm 17.58$ & +8.27 & $\mathrm{~ns}$ \\
\hline number) & Exercise & $53.33 \pm 24.72$ & $61.16 \pm 24.09$ & +14.68 & $\mathrm{~ns}$ \\
\hline Biering Sorensen test (sec) & Control & $43.90 \pm 17.97$ & $42.30 \pm 15.95$ & -3.64 & $\mathrm{~ns}$ \\
\hline & Exercise & $136.08 \pm 31.93$ & $161.42 \pm 38.27$ & +18.61 & 0.00 \\
\hline
\end{tabular}

ns: Not significant.

\section{Flexibility Measurement (cm)}

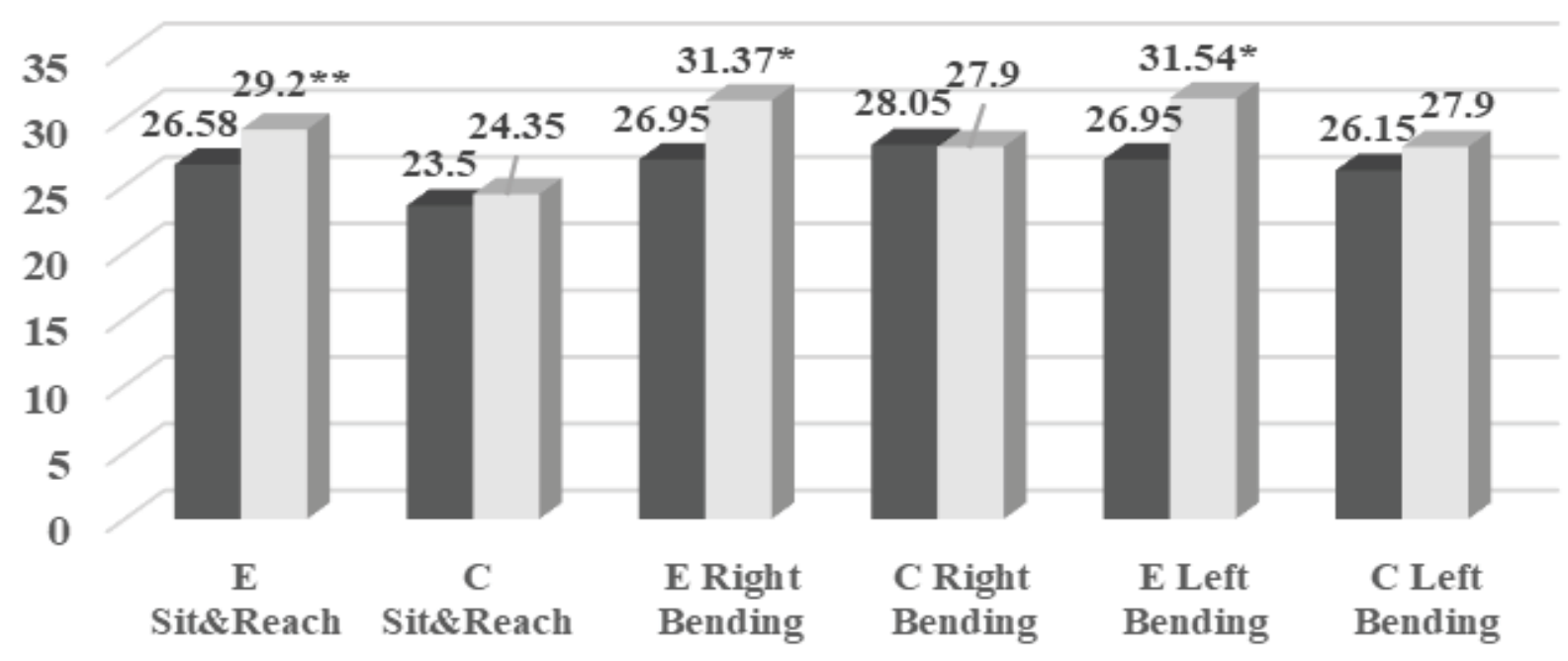

- Pre $\square$ Post

Figure 2: Values of flexibility parameters of the participants. ${ }^{*} p<0.00,{ }^{* *} p<0.01$ (E: Exercise group, C: Control Group).

both groups. There were no differences between groups for spinal ROM values except for T12-L1 extension values before 8 -week training. After 8 weeks core training, a significant increase showed at T12-L1 spine region ROM in exercise group except L5-S1 region. But, when we compare two groups after training, L5-S1 spine region ROM was also showed significant increased in exercise group.

According to the result of $t$-test for the pre and post measurements of all parameters of $Y$ Balance test (Table 5) revealed a significant difference. In this study, dominant foot of all participanst were right. The dynamic balance of the exercise group increased all three directions, especially when their support legs were right leg. However, at control group, significant increase showed at balance at anterior direction when support leg was left leg $(p<0.04)$.

\section{Discussion}

The primary aim of this research was to investigate the effectiveness of a core training on improving the balance, spinal flexibility, and endurance and strength of the core muscles. The findings of this study indicated that 8-week core training has a significant positive effect on physical fitness parameters except body composition in young males.

Anthropometric parameters and body composition values did not change at the end of 8-week core training. Because this training method involves essentially strength exercises, loss of fat may not be expected. Similar results were also observed by Segal, et al. who reported that BIA results such as lean body mass, FM in adult participants did not change after 6 months Pilates exercise [24].

Several studies determined the positive effects of unstable surfaces and devices methods such as Swiss ball and BOSU ball to increase spinal flexibility and core muscle strength in rehabilitations and 


\section{Spinal ROM (dec)}

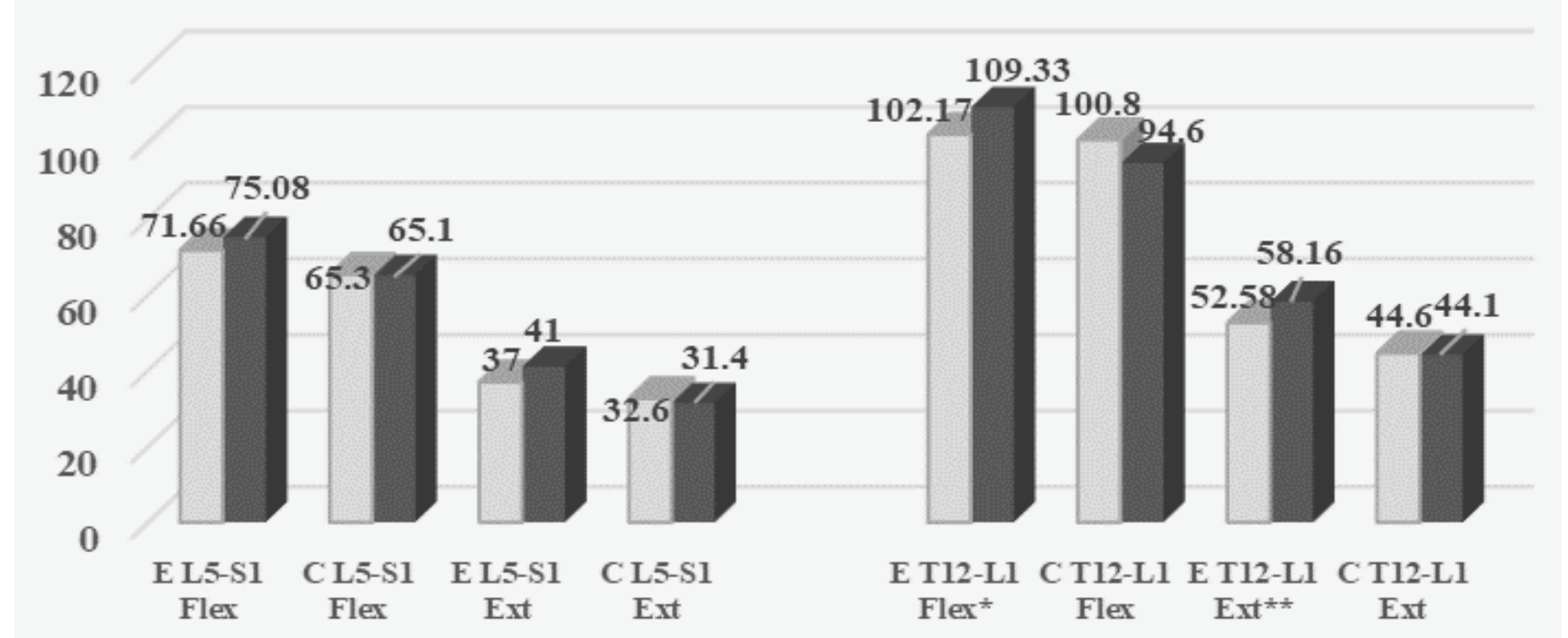

$\square$ Pre $\square$ Post

Figure 3: Measurement of spinal ROM of the participants.

${ }^{*} \mathbf{p}<\mathbf{0 . 0 0 ,}{ }^{*} \mathrm{p}<\mathbf{0 . 0 1}$, (E: Exercise group, C: Control Group, Flex: Flexion, Ext: Extension).

Table 5: Y Balance test values of the participants.

\begin{tabular}{|c|c|c|c|c|c|c|}
\hline \multirow[b]{2}{*}{ Parameters } & \multirow{2}{*}{$\begin{array}{l}\text { Support } \\
\text { Leg }\end{array}$} & \multirow[b]{2}{*}{ Groups } & \multirow{2}{*}{\begin{tabular}{|l} 
pre \\
Mean \pm Sd
\end{tabular}} & \multirow{2}{*}{$\begin{array}{l}\text { Post } \\
\text { Mean } \pm \text { Sd }\end{array}$} & \multirow{2}{*}{$\begin{array}{l}\% \\
\text { Change }\end{array}$} & \multirow[t]{2}{*}{$P$ value } \\
\hline & & & & & & \\
\hline \multirow[t]{4}{*}{ Anterior (cm) } & Left & Exercise & $85.83 \pm 5.30$ & $92.41 \pm 9.52$ & +7.66 & 0.01 \\
\hline & Right & Exercise & $88.00 \pm 5.96$ & $97.83 \pm 10.25$ & +11.17 & 0.01 \\
\hline & Left & Control & $86.20 \pm 7.36$ & $89.70 \pm 7.57$ & +4.00 & 0.04 \\
\hline & Right & Control & $88.80 \pm 8.52$ & $90.00 \pm 8.62$ & +1.35 & ns \\
\hline \multirow[t]{4}{*}{ Posteromedial (cm) } & Left & Exercise & $89.91 \pm 6.35$ & $98.25 \pm 6.22$ & +9.26 & 0.01 \\
\hline & Right & Exercise & $84.50 \pm 7.83$ & $97.75 \pm 7.72$ & +15.68 & 0.00 \\
\hline & Left & Control & $91.10 \pm 9.72$ & $93.70 \pm 7.81$ & +2.85 & ns \\
\hline & Right & Control & $91.40 \pm 6.86$ & $92.10 \pm 5.64$ & +0.76 & ns \\
\hline \multirow[t]{4}{*}{ Posterolateral (cm) } & Left & Exercise & $94.41 \pm 7.47$ & $105.92 \pm 7.40$ & +12.18 & 0.01 \\
\hline & Right & Exercise & $95.83 \pm 9.00$ & $106.33 \pm 9.28$ & +10.95 & 0.00 \\
\hline & Left & Control & $98.00 \pm 8.37$ & $100.40 \pm 9.86$ & +2.44 & ns \\
\hline & Right & Control & $101.11 \pm 9.50$ & $103.00 \pm 9.21$ & +1.87 & ns \\
\hline
\end{tabular}

ns: Not significant.

athletic performance [3,25-28]. Cosio-Lima LM, et al. demonstrated that the Swiss ball exercise group have significantly greater mean change in EMG activations flexion and extension activity and greater balance scores than the floor exercise group after 5 weeks [12]. Behm, et al. ve Sundstrup E, et al. and Cosio Lima, et al. studied EMG activity of the abdominal muscles during abdominal crunches performed on a Swiss ball, and they found that higher abdominal muscle EMG activity show on Swiss ball than performed on the other exercises $[5,12,29]$.

Moreover, the score of Biering Sorensen test determined significantly improvement approximately $18.61 \%$ second in exercise group. Similar to these findings, Sekendiz, et al. determined that improvement back muscle endurance after 12-week Swiss ball core strength training in sedentary women [26]. In contrast to these findings, by some researchers also have been indicated that not significant increase of the backmuscle's endurance after stable surface core training $[10,30]$. As shown in Table 4, there were increases the sit-up and isometric back strength values and it was found that an increase $20.39 \%$ repetation and $10 \%$ kgf respectively, between the pre and post training values. Similarly, after this 8-week training, at muscle strength and back muscle endurance has been observed significant increase in the exercise group which was exercised BOSU ball and Swiss ball, but no significant increase in control group.

In this study, it was assumed that the experimental group did not perform any other strength training except core exercises. Furthermore, it was also assumed that the control group did not any perform strength training. But even so, in the control group, an increase between 
3-11\% which not statistically significant in some strength parameters were seen.

Musculoskeletal flexibility is an important component of health. Also, flexibility is a significant element of physical fitness to reach optimal musculoskeletal function [24]. According to Figure 2, there have been significantly increased to forward and rigth-left lateral flexion score, but this increase is between $2.62 \mathrm{~cm}$ and $4.58 \mathrm{~cm}$. Improving trunk and hamstring flexibility in this study is supported by some research $[24,25,31]$. Especially increase level of the left-right lateral flexibility more than hamsting flexibility have been found in this study. Spesific two BOSU ball movements in this training may positive effected lateral flexibility. Because these exercises have requires the bending of the torso from side, using oblique abdominal muscles.

Comparisons between the exercise and control groups of mean changes in pre and post-training values for spinal ROM measurements are presented in Figure 3. Positive effects of core training were seen at flexion and extension movements especially at upper segments of the spine. In this study, in spide of increasing L5-S1 spine ROM in exercise group, these were not statistically significant. Similarly, at the study of the young females have been found that increasing T12-L1 flexion and extension spine ROM, also L5-S1 extension ROM, after 10-week back muscle strength training [30].

Few studies have been examined that poor balance has a risk factor for injury. To prevent to losing balance during the movement, postural adjustments are performed which require activation of the core musculature to stabilize the lumbar spine. There are loss of balance in many sports drills, and therefore, greater core stability provides a foundation for greater force production in the upper and lower extremities $[3,12]$. The $Y$ Balance test which requires strength, flexibility, ROM and proprioception was developed to solve some of the limitations of the traditional SEBT (Star Excursion Balance Test) methods [22]. Additionally, some researchers emphesed that each reach direction activated the stance lower extremity muscles to a different extent. It was found that in the anterior reach direction the vastus medialis and lateralis were most active and in the posterolateral reach, the biceps femoris and anterior tibialis were most active and in the posteromedial reach direction, anterior tibialis was most active [3].

The results of the 8-week core training exercise protocol showed significant increases in dinamic balance test including at three directions. Our findings are consistent with Sekendiz, et al. and Cosio Lima, et al. who reported that improvement to balance after Swiss ball exercise $[12,25]$. Previous research demonstrated that exercises on unstable equipment such as Swiss ball and BOSU ball significantly improved static balance and postural control [12]. Additionally, Chung, et al. found that improvement to dynamic balance and gait function in stroke patients after 4 weeks core training [32]. In this study, it was recorded that $15.68 \% \mathrm{~cm}$ increase at posteromedial direction and $11.17 \% \mathrm{~cm}$ increase at anterior direction, and $10.95 \% \mathrm{~cm}$ increase at posterolateral direction when right leg was the support leg. This result that it may be explain with dominant leg. Because, in this study, all participants had right foot dominance. Some studies reported that persons with anterior left-right asymmetries greater than 4 $\mathrm{cm}$ on the $Y$ Balance test were potential risk factor for lower extremity injury [33]. And, our findings were also demostrated that difference rigth/left anterior was approximately $3 \mathrm{~cm}$, all participants during pre-training.

\section{Conclusions}

In conclusion, with this study investigated the effect of core training with Swiss ball and BOSU ball on spine flexibility, dynamic balance, back and abdominal muscles strength and endurance, in healthy young males. The results showed that doing short-term exercise positively improved balance, flexibility, endurance and strength, except fat mass. In this context, it can be said that this training program may be a pleasurable alternative training type by coaches and physiotherapists that increased the above-mentioned physical fitness parameters for athletes or sedanter individuals.

\section{References}

1. Richardson C, Jull G, Hodges P, Hides J (1999) Therapeutic exercise for spinal segmental stabilization in low back pain: Scientific Basis and Clinical Approach. Edinburgh (NY): Churchill Livingstone.

2. King MA (2000) Core Stability: Creating a foundation for functional rehabilitation. International Journal of Athletic Therapy and Training 5: 6-13.

3. Willardson JM (2007) Core stability training: applications to sports conditioning programs. J Strength Cond Res 21: 979-985.

4. Willson JD, Dougherty CP, Ireland ML, Davis IM (2005) Core stability and its relationship to lower extremity function and injury. J Am Acad Orthop Surg 13: 316-325.

5. Behm DG, Leonard AM, Young WB, Bonsey WAC, Mackinnon SN (2005) Trunk muscle electromyographic activity with unstable and unilateral exercises. J Strength Cond Res 19: 193-201.

6. Brumitt J (2010) Core assessment and training. Champaign, IL: Human Kinetics.

7. Briggs AM, Greig AM, Wark JD, Fazzalari NL, Bennell $\mathrm{KL}$ (2004) A review of anatomical and mechanical factors affecting vertebral body integrity. Int J Med Sci 1: 170-180.

8. McGill SM (2001) Low back stability: from formal description to issues for performance and rehabilitation. Exerc Sport Sci Rev 29: 26-31.

9. Akuthota V, Ferreiro A, Moore T, Fredericson M (2008) Core stability exercise principles. Curr Sports Med Rep 7: 39-44.

10. Tse MA, McManus AM, Masters RS (2005) Development and validation of a core endurance intervention program: 
implications for performance in college-age rowers. J Strength Cond Res 19: 547-552.

11. Collins $P$ (2009) Core Strength. UK: Meyer \& Meyer Sports.

12. Cosio-Lima LM, Reynolds KL, Winter C, Paolone V, Jones MT (2003) Effects of physioball and conventional floor exercises on early phase adaptations in back and abdominal core stability and balance in women. J Strength Cond Res 17: 721-725

13. Heyward VH (2010) Advanced Fitness Assessment \& Exercise Prescription. Illinois: Human Kinetics Boks, 156168.

14. Macfarlane DJ (2007) Can bioelectric impedance monitors be used to accurately estimate body fat in Chinese adults? Asia Pac J Clin Nutr 16: 66-73.

15. Loenneke JP, Barnes JT, Wilson JM, Lowery RP, Isaacs MN, et al. (2013) Reliability of field methods for estimating body fat. Clin Physiol Funct Imaging 33: 405-408.

16. Liemohn W, Sharpe GL, Wasserman JF (1994) Criterion related validity of the sit-and-reach test. J Strength Cond Res 8: 91-94.

17. Norris CM (2008) Back Stability. Champaign, IL: Human Kinetics, 246-247.

18. Biering-Sørensen F (1984) Physical measurements as risk indicators for low-back trouble over a one-year period. Spine (Phila Pa 1976) 9: 106-119.

19. Waddell G, Somerville D, Henderson I, Newton M (1992) Objective clinical evaluation of physical impairment in chronic low back pain. Spine 17: 617-628.

20. Clarkson HM (2005) Joint motion and function assessment: A Research-Based Practical Guide. Philadelphia: Lippincott Williams \& Wilkins.

21. Ashmen KJ, Swanik CB, Lephart SM (1996) Strength and flexibility characteristics of athletes with chronic low-back pain. Journal of Sports Rehabilitation 5: 275-286.

22. Plisky PJ, Gorman PP, Butler RJ, Kiesel KB, Underwood FB, et al. (2009) The reliability of an instrumented device for measuring components of the star excursion balance test. N Am J Sports Phys Ther 4: 92-99.
23. Shaffer SW, Teyhen DS, Lorenson CL, Warren RL, Koreerat CM, et al. (2013) Y-balance test: a reliability study involving multiple raters. Mil Med 178: 1264-1270.

24. Segal NA, Hein J, Basford JR (2004) The effects of Pilates training on flexibility and body composition: an observational study. Arch Phys Med Rehabil 85: 19771981.

25. Sekendiz B, Cuğ M, Korkusuz F (2010) Effects of Swissball core strength training on strength, endurance, flexibility, and balance in sedentary women. J Strength Cond Res 24: 3032-3040.

26. Stanton R, Reaburn PR, Humphries B (2004) The effect of short-term Swiss ball training on core stability and running economy. J Strength Cond Res 18: 522-528.

27. Saeterbakken AH, Andersen V, Jansson J, Kvellestad AC, Fimland MS (2014) Effects of BOSU ball(s) during sit-ups with body weight and added resistance on core muscle activation. J Strength Cond Res 28: 3515-3522.

28. Norwood JT, Anderson GS, Gaetz MB, Twist PW (2007) Electromyographic activity of the trunk stabilizers during stable and unstable bench press. J Strength Cond Res 21 : 343-347.

29. Sundstrup E, Jakobsen MD, Andersen CH, Jay K, Andersen LL (2012) Swiss ball abdominal crunch with added elastic resistance is an effective alternative to training machines. Int J Sports Phys Ther 7: 372-380.

30. Yaprak Y (2013) The effects of back extension training on back muscle strength and spinal range of motion in young females. Biol Sport 30: 201-206.

31. Phrompaet S, Paungmali A, Pirunsan U, Sitilertpisan $P$ (2011) Effects of pilates training on lumbo-pelvic stability and flexibility. Asian J Sports Med 2: 16-22.

32. Chung EJ, Kim JH, Lee BH (2013) The effects of core stabilization exercise on dynamic balance and gait function in stroke patients. J Phys Ther Sci 25: 803-806.

33. Plisky PJ, Rauh MJ, Kaminski TW, Underwood FB (2006) Star excursion balance test as a predictor of lower extremity injury in high school basketball players. J Orthop Sports Phys Ther 36: 911-919. 